thrift, intelligence and filial love as the foundation without which it is impossible that such creatures should of themselves build up such a singular condition.

It seems to me that hunger, something approaching starvation, is necessary as a beginning of the specialisation. Now we all know that from their capacity to increase with enormous rapidity some insects are subject to great vicissitudes in the matter of food. The locusts, for instance, increase in numbers till, having eaten everything in their native habitat, they leave it in dense masses that obscure the heavens and which devastate vast regions. Of the next brood, immensely more vast in numbers than even these, comparatively a small remnant reach maturity, and scarcely any reproduce their kind. The race grows up again from the few starved individuals too weak to leave the old habitat and of which a few manage to survive long enough to lay some eggs. Those doubtless produce many imperfect insects, but these specialisations are not useful to the race in this caee, and they cannot survive. I think it likely, however, that man could specialise locusts and many other insects in this way without difficulty. I think it likely that he could with great care so specialise fish and possibly fowls and with great patience and much difficulty some of the mammals. I think also that if mules were from a thrifty hoarding stock like squirrels they would be in the habit of feeding the old mare as the worker feed the mother-bee. But while it may be allowable to mention these as interesting possibilities I do not propose to discuss them in this paper.

There is another element which is, I think, very important in fixing the definite type of the workers, and which I had intended to discuss. But while I think that element important in the bee and perhaps absolutely necessary for the still higher specialisation of the ant, I think also that a permanent body of workers is necessarily evolved from the conditions which I have assumed a natural and proper to the primitive bee.

To recapitulate in few words :

I presuppose a primitive bee fertile and affectionate, hoarding and intelligent.

I show that great want will necessarily diminish the number of her eggs.

That it will render some eggs imperfect by deranging the reproluctive organs of the mother.

That consequently some of the offspring will be defective in the reproducing organs.

That while other imperfect bees will generally die before maturity, those imperfect only in the reproductive organs will live if the perfect offspring live.

That some of these being incapable of mating, will not go away for that purpose, but will stay with the mother-bee.

That, having surplus energy to expend, they will use it in accordance with the instinct of the race in gathering and storing food.

That the surplus food will be utilised by the mother-bee, and that therefore this family will be affluent.

That, being affluent, the formerly overtaxed mother will recover her health, and that her offspring will thereafter be perfect.

That consequently these nursemaid-bees will have no suscessors, and the family will therefore be again reduced to want.

That some bees of the same hatch with the nursemaids will be congenitally imperfect, notwithstanding that they leave the mother and find mates.

That the offspring of congenitally imperfect bees will be extremely variable.

That some of this offspring will be unable to reproduce and that they will remain with the mother-bee as nursemaids or helpers.

That these helpers from the congenital imperfections of their mothers will have successors; substantially as is seen among the hive-bees and the humble bees of the present day, and

That the variation thus started will eventually be reduced to a definity type or to definite types-by the survival of the fittest.

That whatever other circumstances may aid in producing the result in question, this is sufficient of itself to account for the specialisation of the bee and the ant into females, males and workers.

SCIENCE IN FRENCH COCHIN CHINA

$W E$ have already referred to an official publication of the French Colonial Government in Saigon, entitled Excur sions et Reconnaissances, which appears every two months, and is wholly devoted to recording the investigations made by French officials in French Cochin China and the neighbouring semiindependent and independent States. The course and results of the numerous scientific missions despatched to these regions by the Ministers of Education and the Colonies, as well as the travels and researches of private individuals, are published in this periodical; and as there are six numbers published annually, of about 200 large octavo pages each, it will readily be perceived, apart altogether from the dearth of information, other than political, with regard to the great Indo-Chinese peninsula, that these volumes form a mine of knowledge of the most authentic and trustworthy description, for the writers are for the most part men who have been specially selected in France to study the subjects with which they deal. Unfortunately, however, the publication is but little known in thi; country, no copy being obtainable in some of our largest official libraries. As it is on sale in Saigon, and doubtless also in Paris, there is no reason why a periodical so valuable should not be made accessible to English students.

We have before us the three last numbers, and from them it is possible to obtain an idea of the scientific work which the French are performing in their new possessions. No department of research escapes their attention, and they are indefatigable in studying the country and people for whose welfare they have now become responsible. In one respect these volumes resemble those of many learned societies in India and elsewhere : they are extremely varied in their contents. Shafts have been driven in all directions, and the result is here; but when we recollect the short period that the French have been even at Saigon, the still shorter period that they have been able to travel in the interior, it will be apparent that no merely private society could accomplish the work done here. The traveller in most parts of Cochin China still requires a guard of twenty or thirty tirailleurs, which can only be provided by the Government. Again, few private persons, however enthusiastic, could afford to spend several years travelling over every part of Cochin China in search of ancient inscriptions, as M. Aymonier has done. Such work as this could, under the circumstances, only be performed with the assistance of Government; and it is greatly to the credit of the French Government that amongst its responsibilities in connection with colonies in the East, it recognises that of thoroughly investigating in a scientific manne the people and territories around them. It has often been said that the French are more sympathetic rulers of subject races than the English, and that they succeed sooner in gaining their affection; whether this be true or not, it is certain that they go the right way to rule properly, by setting themselves at the outset to comprehend what manner of people and of country it is that they are called upon to rule. Science, at any rate, gains by the French practice a consideration which is not very often present to the minds of our colonial rulers.

Geography naturally plays a considerable part in the Exour sions et Reconnoissances, for a great part of Cochin China is still a terra incogrnita. For a like reason there is much that is specially ethnological. Thus, in the numbers before us we have two papers on the Moïs tribes : one by $M$. Nouet, recounting a journey amongst the Mois on the north-eastern frontier; the other, by M. Humann, on the independent Moïs. In the first these curious people are described as slothful and careless, knowing nothing of money, wandering about from place to place in search of subsistence, without any industry beyond producing articles which are absolutely necessary, and always hungry. They are excessively timid, flying into the forest on the approach of a stranger; they have no writing, and appear to have no religion either; they bury and burn the deal, but there are no subsequent ceremonies in connection with the departed. Even those within French territory lead a savage life; their existence is described as, not dying of hunger, rather than positive living. But the race is disappearing slowly from misery and disease ; the prohibition against burning the forests is siid to bear hardly on them, as it is the only method they linow for clearing patches for the cultivation of their rice. The independent tribes, described by M. Humann, are braver than those which are found further south; they can work in iron, and appear more provident and less nomadic. But they live amongst the mountains, whither they have fled before the Annamites on one side and the Siamese on the other.

Dr. Tirant contributes a very long paper, extending over the last three numbers, on the reptiles of Cochin China and Cambodia. It does not profess to be complete, for an exhaustive study of the subject would require collections and books not to 
be obtained at Saigon. That it must be tolerably full, however, appears from the list of serpents, of which there are 87 in all, 17 being poisonous, the rest harmless. The scientific name, the Annamite and Cambodian names, are given in each case.

The inscriptions scattered all over Cambodia, which, like the great ruins of Angkor, have come down from an earlier civilisation which has otherwise disappeared, have attracted much attention, and have now apparently reached a stage in which scholars are violently quarrelling about them. Papers on them, generally accompanied by copies of the inscriptions, appear in every number of the periodical. M. Aymonier was specially sent out from France to study them, and in less than three years he succeeded in obtaining a corfus of about 350 inscriptions. These are in many languages, the principal, however, being in Khmer, or ancient Cambodian; and their examination has thrown much light on the history of Cambodia in ancient times, and possibly on the ethnological problems of the Indo-Chinese peninsula. The general result of the investigation so far, represents the distribution of the inhabitants of the southern part of the peninsula in the first centuries of the Christian era as follows :-The Annamites were still confined to Tonquin, while the Chams occupied the coast of the present Annam ; tribes more or less numerous called Chongs, Kouis, Samre, \&c., occupied the present Cambodia and Southern Laos. Probably their social state was more advanced than that of the tribes still existing between the valley of the Meikong and the coast of Annam. The Laotian people spread along the valley of the Meikong from Luang Prabang in Siam to Lokhon, while the Siamese were scattered about in principalities in the centre of the country now occupied by them. There existed a primitive religion amongst all these tribes : in A pril they rendered homage to the spirits of the high places, and in October they offered of the fruits of the earth to the manes of their ancestors. They knew of the use of iron and made arms and tools for themselves, and they cultivated rice. Then came Indian traders, who penetrated by the Meikong River, founded small colonies, and reduced some of the natives to slavery. They established independent states, and from them we get the name Cambodia, originally a title of honour. Thus the present population of Cochin China is the result of two totally distinct races and civilisations-Indian and the aboriginal native. The inscriptions give the history of the Khmer dynasty down to the twelfth century.

M. Landes writes on the folk-lore of the Annamites, while M. Aymonier has another long paper entitled "Notes on the Laos," being a series of observations made during journeys in the Laos country, which he has not been able to work up into a connected paper on this curious people. They embrace every conceivable subject relating to the Laos: the geography of the country, their ethnological features, customs, rites. There are up to the last issue seventy-nine of these notes, referring to as many different points connected with these tribes.

A lengthy report by Dr. Burck, Director of the Botanical Garden at Buitenzorg, in Java, is printed. It contains an account of his exploration in the highlands behind Padang, on the west coast of Sumatra, in search of the trees which produce guttapercha. The present state of the subject is this: Specimens of guttapercha are found in considerable quantities in trade, but it is impossible with our present knowledge to determine the botanical origin of a single one of these specimens. The Dichopsis gutta (Benth.), the Isonandra gutta of Hooker, is the only species of tree producing guttapercha of which botanical specimens have been sent to Europe. But it has never been exactly and completely described, for no man of science has seen the fruit or seeds in their maturity. No one can at present affirm with certainty the origin of such or such a kind of guttapercha in trade. Dr. Burck maintains that the tree has never been found at Singapore and that since the disappearance of the forests there no one can affirm that the Dichopsis outta can be found in its wild state. The paper is of considerable length and the writer disputes certain statements in the Kew reports with reference to the trees producing guttapercha and the places where they are found. An account of a journey in Siam and a translation of a long Tonquinese poem with copious explanatory notes and an excursus on Annamite literature are the remaining papers of these three numbers, the product of six months' work. At this rate the eastern part of the Indo-Chinese peninsula cannot long remain unknown to Europe.

Since the above was in type we have received the succeeding number (vol. ix. No. 22) of the periodical here referred to. It contains a report from M. Aymonier on a further journey of his in search of inscriptions, and describing in some detail the tribe of Chams in Cambodia. He promises a complete work later on this tribe in the province of Binthuan, which have been almost wholly unknown hitherto. The same writer concludes his valuable notes on the Laos, the present instalment dealing with the Kouis, the Khmers, and the province of Korat. These notes occupy more than half the whole number, and, in the present state of our knowledge of the Laos tribes, are simply invaluable, supplying as they do the results of long and close observation on the part of the only European traveller who has yet had an opportunity of living and travelling amongst them. M. Baux has a short encyclopædia sort of article on tea, which is of no especial note. M. Landes continues his folk-lore of Annamites, under the title "Contes et Légendes Annamites." So far he has given fifty popular tales and fables, in which we find many old friends. Androcles and the lion reappear, for example, as the midwife and the tigress, the reward being a pig caught by the latter and carried as a present to the woman. Dr. Tirant, having concluded his study of the reptiles, commences in this number a paper on the fishes of Lower Cochin-China and Cambodia. Fishes play here a preponderating zoological rôle, Southern Indo-China forms an ichthyological province closely allied with Malayasia; Lower Cochin-China in particular has curious affinities in this respect with Borneo. The present number contains only the first instalment of Dr. Tirant's "Notes," as he modestly styles a paper of great research and investigation.

\section{ON THE MEASUREMENT OF MOVEMENTS OF THE EARTH, WITH REFERENCE TO PROPOSED EARTHQUAKE-OBSERVATIONS} ON BEN NEVIS ${ }^{1}$

MEASUREMENTS of earth-movements are of two distinct types. In one type the thing measured is the displacement, or one or more components of the displacement, of a point on the earth's surface. For this purpose the mechanical problem is to obtain a steady point, to be used as an origin of reference, and this is effected by making use of the resistance which a mass opposes to any change of motion. This may be called the Inertia method of observing earth-movements. It is applicable to ordinary earthquakes, and also to the more minute earth-tremors which would pass unnoticed if instrumental means of detecting their presence were not employed. The steady point is to be obtained by suspending a heavy mass (with one, two, or three degrees of freedom) in such a manner that its equilibrium is very nearly neutral. Any moderately sudden displacement of the ground in the direction in which the mass has freedom to move leaves the mass almost undisturbed, and the displacement of the ground is therefore easily measured or recorded by a suitable autographic arrangement, which must be so designed as to introduce exceedingly little friction.

The second type of measurement is that in which the thing measured is any change in the inclination of the surface of the ground relatively to the vertical. Movements of this class have been examined by d'Abbadie and Plantamour, and also by G. $\mathrm{H}$. and $\mathrm{H}$. Darwin, who have given the results of their observations to the British Association in two reports on the lunar disturbance of gravity (1882-3). Perhaps the most convenient name for these movements is " earth-tiltings." They are measured by what may be called the Equilibrium method. A pendulum, suspended in a viscous fluid, is employed to show, by its equilibrium position, the true direction of the vertical, and that is compared with the direction of a line which is fixed relatively to the surface of the ground ; or, instead of a pendulum, a dish of mercury or a pair of spirit-levels are employed to define a truly horizontal surface, and the tilting of the earth's surface relatively to that is observed. This method is practicable only when the displacements of the surface have so great a vertical amplitude, in comparison with their horizontal wavelength, that the slope of the wave is sensible; and, further, only when the changes of slope occur slowly enough to put the inertia of the pendulum or fluid out of account.

On the other hand, the inertia method is applicable only when the displacements have so short a period, in comparison with their amplitude, that the acceleration of the ground, during

x Paper read before Section A of the British Association at Aberdeen, by Prof. J. A. Ewing, of University College, Dundee. (Abstract.) 